Available online on 15.1.2019 at http://ujpr.org
Universal Journal of Pharmaceutical Research
An International Peer Reviewed Journal
Open access to Pharmaceutical research

\title{
PSEUDOMONAS AERUGINOSA SKIN-NASOPHARYNGEAL COLONIZATION IN THE IN-PATIENTS: PREVALENCE, RISK FACTORS AND ANTIBIOTIC RESISTANCE IN TERTIARY HOSPITALS IN SANA'A CITY-YEMEN
}

Rahma Taher Farea AL-Magrami , Hassan Abdulwahab Al-Shamahy* (iD)

Medical Microbiology and Clinical Immunology, Faculty of Medicine and Health Sciences, Sana'a University, Republic of Yemen.

\section{ABSTRACT}

Objective: Pseudomonas aeruginosa is one of most important cause of healthcare-associated infections. This active surveillance cross sectional study was aimed to determine the rate of $P$. aeruginosa colonization among inpatients at three tertiary hospitals in Sana'a city. In addition, to determine risk factors of colonization and the antibiotic susceptibility of the isolated P. aeruginosa. Methods: The study included 327 inpatients. Skin and nasopharyngeal swabs were collected from all participated patients and data were collected by predesigned questionnaire. Standard methods of isolation and identification were used to isolate bacteria in pure culture then identify. Also, antibiotic sensitivity for isolated $P$. aeruginosa was determined by the disc diffusion method. 42 patients $(12.8 \%)$ were colonized with $P$. aeruginosa on skin and nasopharyngeal.

Results: The significant risk factors of colonization were male patients $(\mathrm{OR}=2.5)$, older age $(\mathrm{OR}=2.2)$, burn ward $(\mathrm{OR}=37)$, long stay in hospital $(\mathrm{OR}=4)$ and burn as underlying disease $(\mathrm{OR}=45)$. The isolated $P$. aeruginosa were completely resistant $(100 \%)$, to Aztroneome, Ceftriaxone, and Ciprofloxacine; and the rates of resistant were ranged between 83.3-85.7\% for Amikacin, Ampicillin sulbactam Levofloxacin. Also the rates were $71.4 \%$ for Netilmicin and $92.9 \%$ for chloramphenicol. Moreover, the rates of resistant were low for Gentamicin (35.7\%), Imipenem (11.9\%), Pipracillin Tazobactam (11.9\%), Ticaracillin calvulanic acid (31\%) and Colistin sulphat (14.3\%).

Conclusion: In conclusion, this study has highlighted the role of hospitalization as a significant risk for P. aeruginosa colonization; concerted and coordinated efforts are required both in the hospital and community to tackle this. These data emphasize the need to identify hospitalized patients colonized with $P$. aeruginosa on admission. Prediction rules or rapid diagnostic testing will help clinicians more appropriately choose empiric antibiotic therapy if subsequent infections occurred.

Keywords: Active surveillance, antibiotic resistance, colonization, Pseudomonas aeruginosa, risk factors, tertiary hospitals.

Article Info: Received 2 November 2018; Revised 5 December; Accepted 28 December, Available online 15 January 2019

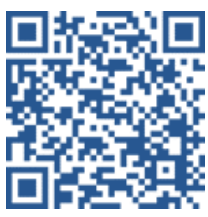
Cite this article-

AL-Magrami RTF, Al-Shamahy HA. Pseudomonas aeruginosa skin-nasopharyngeal colonization in the inpatients: prevalence, risk factors and antibiotic resistance in tertiary hospitals in Sana'a city- Yemen. Universal Journal of Pharmaceutical Research 2018; 3(6): 17-22.

DOI: https://doi.org/10.22270/ujpr.v3i6.219

Address for Correspondence

Prof. Hassan A. Al-Shamahy, Faculty of Medicine and Heath Sciences, Sana'a University, P.O. Box 775 Sana'a, Yemen. Phone: +967-770299847, E-mail: shmahe@yemen.net.ye

\section{INTRODUCTION}

Bacterial colonization in general and $P$. aeruginosa colonization in hospitalized patients are important cause of healthcare-associated infections worldwide ${ }^{1}$. In the United States, it is the $6^{\text {th }}$ most common cause of healthcare-associated infections, accounting for $7.1 \%$ of all hospital infections ${ }^{2}$. The choice of empiric antibiotics in the hospital setting is difficult. There needs to be a balance between excessively broad coverage and too narrow coverage. Empiric antibiotic coverage that covers $P$. aeruginosa but is broader than necessary may lead to the emergence of $P$. aeruginosa and other intestinal bacteria that are resistant to those broad spectrum antibiotics. In contrast, empiric therapy that does not cover $P$. aeruginosa may lead to poor outcomes for in-patients eventually found to have $P$. aeruginosa infection. Improvements in current understanding of which patients require broadspectrum empiric coverage versus situations in which narrower spectrum agents may be appropriate would be valuable from an antimicrobial stewardship perspective. Knowledge of whether a patient is colonized with $P$. aeruginosa can be helpful in guiding selection of empiric antibiotics for suspected sepsis in the hospital setting. Colonization with $P$. aeruginosa is associated with subsequent infection with the same strain of P. aeruginosa ${ }^{3,4}$. The objectives of this active surveillance cross sectional study were as follows:

a) Determine the prevalence of $P$. aeruginosa colonization on Inpatients; b) Determine risk factors 
for $P$. aeruginosa colonization; and c) Determine the antibiotic susceptibility of the isolated $P$. aeruginosa.

\section{SUBJECTS AND METHODS}

Site of the study

An active surveillance cross sectional study was conducted in in-patients admitted to three tertiary hospitals in Sana'a city: namely: Al-Jumhori hospital, Al-Kuwait hospital and Yemen-Germen hospital, between January 1, 2017, and May 30, 2017. The three hospitals are 1816-bed tertiary care facilities.

\section{Ethical Consideration}

Ethical clearance for the study was taken from the Faculty of Medicine and Health Sciences Research Review Committee. A written permission was also taken from the administrative Managers of the AlJumhori hospital, Al-Kuwait hospital and YemenGermen hospital. Informed Consent was taken from the patients before the questionnaire was filled.

Table 1: The association between skin-nasopharyngeal pseudomonas aeruginosa colonization and sex and age of in-patients, Sana'a city, Yemen.

\begin{tabular}{|c|c|c|c|c|c|c|c|c|}
\hline \multirow[t]{2}{*}{ Characters } & \multicolumn{2}{|c|}{$\begin{array}{c}\text { Positive } P \text {. aeruginosa } \\
\text { colonization }\end{array}$} & \multicolumn{2}{|c|}{$\begin{array}{c}\text { Negative } P \text {. aeruginosa } \\
\text { colonization }\end{array}$} & \multirow[t]{2}{*}{ OR } & \multirow[t]{2}{*}{ CI } & \multirow[t]{2}{*}{$\chi^{2}$} & \multirow[t]{2}{*}{$\mathbf{P}$} \\
\hline & No & $\%$ & No & $\%$ & & & & \\
\hline \multicolumn{9}{|l|}{ Sex } \\
\hline Male & 33 & 16.4 & 168 & 83.6 & 2.5 & $1.1-5.5$ & 5.9 & 0.01 \\
\hline Female & 9 & 7.1 & 117 & 92.9 & 0.39 & $0.18-0.8$ & 5.9 & 0.01 \\
\hline \multicolumn{9}{|l|}{ Age groups } \\
\hline$\leq 19$ years & 2 & 14.3 & 12 & 85.7 & 1.1 & $0.2-5.2$ & 0.02 & 0.8 \\
\hline 20-29 years & 4 & 6.3 & 60 & 93.7 & 0.3 & $0.1-1.1$ & 3.1 & 0.07 \\
\hline $30-39$ years & 5 & 9.6 & 47 & 90.4 & 0.7 & $0.2-1.8$ & 0.46 & 0.47 \\
\hline $40-49$ years & 6 & 10.5 & 51 & 89.5 & 0.7 & $0.3-1.8$ & 0.27 & 0.6 \\
\hline$\geq 50$ years & 25 & 17.9 & 115 & 82.1 & 2.2 & $1.1-4.2$ & 5.4 & 0.01 \\
\hline Total & 42 & 12.8 & 285 & 87.2 & & & & \\
\hline
\end{tabular}

Table 2: The association between skin-nasopharyngeal pseudomonas aeruginosa colonization and type of wards of in-patients, Sana'a city, Yemen.

\begin{tabular}{|c|c|c|c|c|c|c|c|c|}
\hline \multirow[t]{2}{*}{ Wards } & \multicolumn{2}{|c|}{$\begin{array}{c}\text { Positive } \\
\text { colonization }\end{array}$} & \multicolumn{2}{|c|}{$\begin{array}{c}\text { Negative } \\
\text { colonization }\end{array}$} & \multirow[t]{2}{*}{$\mathbf{O R}$} & \multirow[t]{2}{*}{ CI } & \multirow[t]{2}{*}{$\chi^{2}$} & \multirow[t]{2}{*}{$P$} \\
\hline & No & $\%$ & No & $\%$ & & & & \\
\hline $\mathrm{ICU} n=69$ & 9 & 13 & 60 & 87 & 1 & $0.41-2.5$ & 0.003 & 0.95 \\
\hline Burn $n=48$ & 30 & 62.5 & 18 & 37.5 & 37 & $16.2-84$ & 123 & $<0.001$ \\
\hline Medical wards $n=210$ & 3 & 1.4 & 207 & 98.6 & 0.02 & $0.008-0.09$ & 68 & $<0.001$ \\
\hline Total $n=327$ & 42 & 12.8 & 285 & 87.2 & & & & \\
\hline
\end{tabular}

\section{Survey procedure and Laboratory Analysis}

Skin and nasopharyngeal swabs collected from inpatients hospitalized in different wards. Clinical and demographic data were collected for all participants' patients. Skin and nasopharyngeal swabs were collected using standard collection techniques, and inoculated on appropriate bacteriological media, including blood agar and Mac-Conkey. Then plates were incubated aerobically at $37^{\circ} \mathrm{C}$ for $18-24 \mathrm{~h}$. Confirmatory tests include production of the bluegreen pigment pyocyanin on Cetrimide agar and growth at $42^{\circ} \mathrm{C}$ also done. Also, the identification of isolates was made according to standard methods ${ }^{5}$. The identification was made with basic microbiological methods using colony morphology, Gram staining, oxidase, Indole, catalase and coagulase tests etc ${ }^{5}$.

\section{Antimicrobial susceptibility test}

Antimicrobial susceptibility test for $P$. aeruginosa isolates were performed on Mueller-Hinton agar plates by the Kirby-Bauer disc diffusion method ${ }^{5}$. The isolates were tested for their susceptibility against 13 antimicrobial agents that are used in Yemen. Standardized suspension of $P$. aeruginosa inoculums was compressed to $0.5 \mathrm{McF}$ arland standard turbidity, and then inoculated on 3 Muller-Hinton agar plates using a sterile cotton swab by streaking the swab over the entire sterile agar surface 3 times. The plates then allowed drying and antimicrobial discs were placed at the recommended distance from each other. All plates were aerobically incubated at $37^{\circ} \mathrm{C}$ for $24-48$ hours before the zones size were record (diameter of inhibition zones was measured and recorded in millimeters with the help of sliding calipers, and an organism was labeled as sensitive or resistance as per CLSI guidelines 5 .

Data analysis

The analysis of data was done by Epi Info version 6 statistical program (CDC, Atlanta, USA), where the chi-square $\left(\chi^{2}\right)$ and probability value $(p)$ was calculated for the test of significance. In addition, Odd's ratio (OR), $95 \%$ confidence interval $(95 \% \mathrm{CI})$ were added to estimate the risk factors of skin or nasopharyngeal colonization $P$. aeruginosa on inpatients.

\section{RESULTS}

The detailed results of this study are presented in 5 Tables. Table 1 shows the association between skin, nasopharyngeal $P$. aeruginosa colonization and sex and age of the in-patients. Table 2 demonstrates the association between skin-nasopharyngeal $P$. aeruginosa colonization and type of wards, Table 3 illustrates the association between skinnasopharyngeal $P$. aeruginosa colonization and duration of hospitalization. Table 5 explains the 
association between skin, nasopharyngeal $P$. aeruginosa colonization and underlying diseases and Table 6 shows the antibiotic sensitivity of isolated $P$. aeruginosa. Total 42 patients $(12.8 \%)$ were colonized with $P$. aeruginosa on in skin and nasopharyngeal. The significant risk factors of colonization were male patients $(\mathrm{OR}=2.5,95 \% \mathrm{CI}=1.1-5.5, p=0.01)$, older age $(\mathrm{OR}=2.2,95 \% \quad \mathrm{CI}=1.1-4.2, \quad p=0.01), \quad$ Burn ward $(\mathrm{OR}=37,95 \% \mathrm{CI}=16.2-84, p<0.001)$, long stay in hospital (OR=4, 95\% CI $=2.0-7.8, p<0.001)$ and burn as underlying disease $(\mathrm{OR}=45,95 \% \quad \mathrm{CI}=19-105$, $p<0.001)$. The isolates of $P$. aeruginosa were completely resistant (100\%), to Aztroneome, Ceftriaxone, and Ciprofloxacine and the rates of resistant were between 83.3-85.7\% for Amikacin, Ampicillin sulbactam Levofloxacin, $71.4 \%$ for Netilmicin and $92.9 \%$ for chloramphenicol. Moreover, the rates of resistant were low for Gentamicin (35.7\%), Imipenem (11.9\%), Pipracillin tazobactam (11.9\%), Ticaracillin calvulanic acid $(31 \%)$ and Colistin sulphat $(14.3 \%)$

Table 3: The association between skin-nasopharyngeal pseudomonas aeruginosa colonization and duration of hospitalization for in-patients, Sana'a city, Yemen.

\begin{tabular}{|c|c|c|c|c|c|c|c|c|}
\hline \multirow[t]{2}{*}{ Duration } & \multicolumn{2}{|c|}{$\begin{array}{c}\text { Positive } \\
\text { colonization }\end{array}$} & \multicolumn{2}{|c|}{$\begin{array}{c}\text { Negative } \\
\text { colonization }\end{array}$} & \multirow[t]{2}{*}{ OR } & \multirow[t]{2}{*}{ CI } & \multirow[t]{2}{*}{$\chi^{2}$} & \multirow[t]{2}{*}{$P$} \\
\hline & No & $\%$ & No & $\%$ & & & & \\
\hline $1-7$ days $n=129$ & 6 & 4.7 & 123 & 95.3 & 0.2 & $0.08-0.51$ & 12.7 & $<0.001$ \\
\hline $8-16$ days $n=120$ & 15 & 12.5 & 105 & 87.5 & 0.9 & $0.5-1.8$ & 0.02 & 0.88 \\
\hline$\geq 17$ days $n=78$ & 21 & 27 & 57 & 73 & 4.0 & $2-7.8$ & 18.1 & $<0.001$ \\
\hline Total $n=327$ & 42 & 12.8 & 285 & 86.7 & & & & \\
\hline
\end{tabular}

Table 4: The association between skin-nasopharyngeal pseudomonas aeruginosa colonization and underlying diseases for in-patients, Sana'a city, Yemen.

\begin{tabular}{|c|c|c|c|c|c|c|c|c|}
\hline \multirow[t]{2}{*}{ Underlying disease } & \multicolumn{2}{|c|}{$\begin{array}{c}\text { Positive } \\
\text { colonization }\end{array}$} & \multicolumn{2}{|c|}{$\begin{array}{c}\text { Negative } \\
\text { colonization }\end{array}$} & \multirow[t]{2}{*}{ OR } & \multirow[t]{2}{*}{ CI } & \multirow[t]{2}{*}{$\chi^{2}$} & \multirow[t]{2}{*}{$\mathbf{P}$} \\
\hline & No & $\%$ & No & $\%$ & & & & \\
\hline Burn $n=45$ & 30 & 66.7 & 15 & 33.3 & 45 & $19-105$ & 135 & $<0.001$ \\
\hline Cardiovascular diseases $n=66$ & 1 & 1.5 & 65 & 98.5 & 0.08 & $0.01-0.6$ & 9.4 & 0.002 \\
\hline Malignancy $n=72$ & 8 & 11.1 & 64 & 88.9 & 0.8 & $0.3-1.8$ & 0.24 & 0.61 \\
\hline Operation $n=21$ & 1 & 4.8 & 20 & 95.2 & 0.3 & $0.04-2.4$ & 1.3 & 0.25 \\
\hline Liver diseases $n=84$ & 1 & 1.2 & 83 & 98.8 & 0.05 & $0.008-0.4$ & 13.7 & $<0.001$ \\
\hline Respiratory diseases $n=39$ & 1 & 2.6 & 38 & 97.4 & 0.15 & $0.02-1.1$ & 4.1 & 0.04 \\
\hline Total $n=327$ & 42 & 12.8 & 285 & 87.2 & & & & \\
\hline
\end{tabular}

\section{DISCUSSION}

In present study, there was a significant rate of skinnasopharyngeal $P$. aeruginosa colonization in inpatients equal to $12.8 \%$ (Table 1). Current result is comparable to that reported from district hospitals in $\mathrm{UK}^{6}$. Furthermore current study is similar to that reported previously by Parkins et al., in which hospitalization was a risk factor for bacterial colonization $^{7}$. This association can be explained by that high rate of direct transmission of infectious agents in hospitals, in which this involves a direct body surfaceto-body surface contact and physical transfer of microorganisms between a susceptible host and an infected or colonized person, such as when a person turns a patient, gives a patient a bath, or performs other patient-care activities that require direct personal contact. Direct-contact transmission also can occur between two patients, with one serving as the source of the infectious microorganisms and the other as a susceptible host ${ }^{8}$; or by indirect-contact transmission, which involves contact of a susceptible host with a contaminated intermediate object, usually inanimate, such as contaminated instruments, needles, or dressings, or contaminated gloves that are not changed between patients. In addition, the improper use of saline flush syringes, vials, and bags has been implicated in disease transmission in the US, even when healthcare workers had access to gloves, disposable needles, intravenous devices, and flushes ${ }^{8}$.
Additionally in current study, there was significant association between male patients and skinnasopharyngeal $P$. aeruginosa colonization in inpatients equal to 2.5 times with $\mathrm{CI}=1.1-5.5$ and $P=0.01$, while no significant association was found with female. Current result is similar to that reported previously by several studies in which male sex was a risk factor associated with contracting bacterial colonization in inpatients ${ }^{1,7-12}$. As well, there was significant association between older age group $\geq 50$ years and skin-nasopharyngeal $P$. aeruginosa colonization in inpatients equal to 2.2 times with $\mathrm{CI}=1.1-4.2$ and $P=0.01$, while no significant association was found with younger age groups (Table 1). This result is parallel to that reported previously by studies in USA and Europe in which older age group was a risk factor associated with contracting bacterial colonization in hospitalized patients ${ }^{1,10-12}$.

When it was considered that the association between skin-nasopharyngeal $P$. aeruginosa colonization and type of wards, there was significant associated OR equal to 37 times with $\mathrm{CI}=16.2-84$ and $P<0.0001$ with burn wards (Table 2). This result is similar to that reported by Lyczak, et al., in which burn wards were associated risk factor with bacterial colonization in inpatients ${ }^{13}$. This association can be explained by that original thermal injury creates a breach in the surface of the skin which make it more susceptible to colonization with micro-organisms, and $P$. 
aeruginosa use quorum sensing to induce the production of virulence factors such as proteases, hemolysins, exotoxins A and pyocyanin which help bacteria to colonized $^{14}$. However there was no significant association between ICU wards and skinnasopharyngeal $P$. aeruginosa colonization (Table 2). This result is different from that reported by Harris et $a l .{ }^{6}$ in which significant association between ICU patients and colonized with $P$. aeruginosa after admission to hospitals. Current negative result might be due to our small sample size. As soon as we considered the association between skinnasopharyngeal bacterial colonization and duration of hospitalization, there was significant associated OR equal to 4.0 times with $\mathrm{CI}=2.0-7.8$ and $P<0.001$ with $\geq 17$ days of hospitalization (Table 3 ). This result is similar to that reported elsewhere in which longer period of hospitalization was a hazard factor of bacteria colonization including $P$. aeruginos $a^{6,14}$. This result can be explained by that contracting of bacteria by patient increase with longer period of exposure to micro-organisms present in hospital.

Table 5: Antibiotic sensitivity of isolated pseudomonas aeruginosa.

\begin{tabular}{lcccc}
\hline Antimicrobial agents & \multicolumn{2}{c}{ Sensitive } & \multicolumn{2}{c}{ Resistance } \\
\cline { 2 - 5 } & Number & \% & Number & \% \\
\hline Amikacin & 6 & 14.3 & 36 & 85.7 \\
Ampicillin sulbactam & 7 & 16.7 & 35 & 83.3 \\
Aztroneome & 0 & 0.0 & 42 & 100 \\
Ceftriaxone & 0 & 0.0 & 42 & 100 \\
Chloramphenicol & 3 & 7.1 & 39 & 92.9 \\
Ciprofloxacine & 0 & 0.0 & 42 & 100 \\
Gentamicin & 27 & 64.3 & 15 & 35.7 \\
Imipenem & 37 & 88.1 & 5 & 11.9 \\
Levofloxacin & 6 & 14.3 & 36 & 85.7 \\
Netilmicin & 12 & 28.6 & 30 & 71.4 \\
Pipracillin tazobactam & 37 & 88.1 & 5 & 11.9 \\
Ticaracillin calvulanic acid & 29 & 69 & 13 & 31 \\
Colistin sulphat & 36 & 85.7 & 6 & 14.3 \\
\hline
\end{tabular}

When we considered the association between skinnasopharyngeal $P$. aeruginosa colonization and type of underlying diseases, there was no association with malignancy (Table 4). This result is dissimilar to all reports in which malignancy was a risk factor for colonization bacteria in hospitalized patients ${ }^{6}$. However, there was significant association between $P$. aeruginosa colonization and burn with $\mathrm{OR}=45$, $\mathrm{CI}=19-105, p<0.001$ (Table 4). This result is similar to that reported by previous reports ${ }^{8-13}$ in which burn was risk factor of $P$. aeruginosa colonization ${ }^{6-13}$. This association can be explained by that original thermal injury creates a breach in the surface of the skin which make it more susceptible to colonization with microorganisms, and $P$. aeruginosa use quorum sensing to induce the production of virulence factors such as proteases, hemolysins, exotoxins $\mathrm{A}$ and pyocyanin which help bacteria to colonized as stated previously in the discussion of Burn ward ${ }^{14}$.

This study was carried out because of the knowledge of $P$. aeruginosa prevalence and the current antimicrobial profile is necessary in selection of appropriate empirical treatment of these infections and control of $P$. aeruginosa in hospitals is essential. $P$. aeruginosa is a common nosocomial pathogen ${ }^{15}$ that causes infections with a high mortality rate ${ }^{16}$. This latter is, in part, attributable to the organism's intrinsically high resistance to many antimicrobials and the development of increased, particularly multidrug resistance in healthcare settings ${ }^{17}$, both of which complicate anti-pseudomonal chemotherapy. Indeed, numerous studies point to a link between multidrug resistance and increased morbidity/ mortality, as well as increased length of hospital stay and increased hospital costs ${ }^{18}$. In current study the isolated $P$. aeruginosa was completely resistant (100\%), to Aztroneome, Ceftriaxone, and Ciprofloxacine. This result is different from that reported in USA in which the rate of Aztroneome, Ceftriaxone, and Ciprofloxacine resistant was not more than $52.2 \%$. Also the incidence of Aztroneome, Ceftriaxone, and Ciprofloxacine resistant in the European countries has been documented by Lambert et al., ${ }^{16}$ in which the rates were ranged from $50-72 \%$. These high rates in current study can be explained by the fact that acquisition of resistance genes [e.g., those encoding $\quad \beta$-lactamases ${ }^{20}$ and aminoglycoside modifying enzymes ${ }^{21}$ via horizontal gene transfer can and do drive antimicrobial/multidrug resistance development in $P$. aeruginosa, more commonly mutations of chromosomal genes (target site, efflux mutations $)^{22}$. The results of current study showed higher rates of resistant of P. aeruginosa (83.3-85.7\%) to Amikacin, Ampicillin sulbactam, and Levofloxacin. This result is different from study carried out at Canada in 2010 which showed significant variable susceptibility pattern with lower resistance rates to Amikacin, (25\%), Ampicillin sulbactam (35\%), and Levofloxacin $(25 \%)$. There were low resistant rates of resistant for current isolated $\mathrm{P}$. aeruginosa for Gentamicin (35.7\%), Imipenem (11.9\%), Pipracillin Tazobactam (11.9\%), and Ticaracillin calvulanic acid $(31 \%)$. The current results are similar to that reported from USA in which resistance rates to these antibiotics were not exciding $30 \%{ }^{17}$. Owing to the increased prevalence of multidrug-resistant $P$. aeruginosa, "older" antimicrobials like the polymyxins (polymyxin B and colistin) are back in favor, with earlier issues surrounding nephrotoxicity largely dealt with previous study ${ }^{23,24}$. The rate in current study for 
Colistin sulphat resistant was $14.3 \%$. This rate is similar to that reported from Russia and Western Europe $^{23,24}$.

\section{CONCLUSION}

The study have been highlighted the role of hospitalization as a significant risk for $P$. aeruginosa colonization; concerted and coordinated efforts are required both in the hospital and community to tackle this. Elimination of health care-associated infections is a priority of the Ministry of Health and Population. Continued improvements in patient safety depend on maintaining a comprehensive understanding of the epidemiology of health care-associated infections. Currently, no single Yemen surveillance study can provide estimates of the burden of all types of such infections across hospital care patient populations. Effective antimicrobial activity as well as cost effectiveness should be considered in drugs prescribed for $P$. aeruginosa infections. Oral dosing options for antibiotics can allow earlier discharge of hospitalized patients and minimize the chances of $P$. aeruginosa multi-resistant emergence. Good hospital infection control measures prove to be the main stay against these infections because antibiotics can never be an effective alternative to good medical practice.

\section{Limitation}

This study has a number of limitations. Some data is missing and the numbers are small. Only skin and nasopharyngeal specimens were collected. In the protocol of the study rectal colonization was concerned, but most patients were refused to give rectal swab so no more than skin and nasopharyngeal specimens were collected. No molecular studies were used to categories samples further, in order to determine cross resistance or resistance mechanisms. Nevertheless, we believe this study adds further information to the epidemiology of a significant pathogen in the hospital setting in Sana'a city. In addition, although we are confident that the studied hospitals are representative of hospitals within Sana'a city, they may not be representative of all Yemen hospitals.

\section{ACKNOWLEDGEMENTS}

The authors would like to acknowledge Sana'a University, and the Microbiology Department of the National Centre of Public Health Laboratories (NCPHL) Sana'a, Yemen which provided working space.

\section{AUTHOR'S CONTRIBUTION}

This research work is part of A M.Sc. thesis. The candidate is the first author (RTFA) who conducted the laboratory and field works; and wrote up the thesis. The corresponding author (HAA) supervised the laboratory and field works, revised and edited the thesis draft and the manuscript.

\section{CONFLICT OF INTEREST}

No conflict of interest associated with this work.

\section{REFERENCES}

1. Suárez C, Peña C, Gavaldà L, et al. Influence of carbapenem resistance on mortality and the dynamics of mortality in Pseudomonas aeruginosa bloodstream infection. Int J Infect Dis 2010; 14Suppl 3:e73-8. https://doi.org/10.1016/j.ijid.2009.11.019

2. Magill SS, Edwards JR, Bamberg W, et al. Multistate pointprevalence survey of health care-associated infections. N Engl J Med 2014; 370:1198-1208. https://doi.org/10.1056/NEJMoa1306801

3. Thuong M, Arvaniti K, Ruimy R, et al. Epidemiology of Pseudomonas aeruginosa and risk factors for carriage acquisition in an intensive care unit. J Hosp Infect 2003; 53:274-282. https://doi.org/10.1053/jhin.2002.1370

4. Nesher L, Rolston KV, Shah DP, et al. Fecal colonization and infection with Pseudomonas aeruginosa in recipients of allogeneic hematopoietic stem cell transplantation. Transpl Infect Dis 2015; 17:33-38.

https://doi.org/10.1111/tid.12323

5. Cheesbrough MC. District Laboratory Practice in Tropical Countries. $1^{\text {st }}$ Edn, Cambridge University Press, Cambridge 2006, UK. https://doi.org/10.1017/CBO9780511543470

6. Harris AD, Jackson SS, Robinson G et al. Pseudomonas aeruginosa colonization in the ICU: Prevalence, risk factors and clinical outcomes. Infect Control Hosp Epidemiol 2016; 37(5): 544-548. https://doi.org/10.1186/cc13697

7. Parkins MD, Gregson DB, Pitout JD, et al. Populationbased study of the epidemiology and the risk factors for $P$. aeruginosa blood stream infection. Infection 2010; 38:2532. https://doi.org/10.1007/s15010-009-9145-9

8. Jain SK, Persaud D, Perl TM, et al. Nosocomial malaria and saline flush. Emerging Infect. Dis 2005; 11(7): 1097 9. https://doi.org/10.3201/eid1107.050092

9. Enoch DA, Julie Kuzhively, Andrew S, et al. Pseudomonas aeruginosa Bacteraemia in two UK district Hospitals. Infect Dis Rep. 2013; 5(1): e4. https://doi.org/10.4081/idr.2013.e4

10. Cheong HS, Kang CI, Wi YM, et al. Inappropriate initial antimicrobial therapy as a risk factor for mortality in patients with community-onset Pseudomonas aeruginosa bacteraemia. Eur J Clin Microbiol Infect Dis 2008; 27:1219-25. https://doi.org/10.1093/jac/dkg403

11. Kang CI, Kim SH, Kim HB, et al. Pseudomonas aeruginosa bacteremia: risk factors for mortality and influence of delayed receipt of effective antimicrobial therapy on clinical outcome. Clin Infect Dis 2003;7:745-51. https://doi.org/10.1086/377200

12. Micek ST, Lloyd AE, Ritchie DJ, et al. Pseudomonas aeruginosa bloodstream infection: importance of appropriate initial antimicrobial treatment. Antimicrob Agents Chemother 2005; 49:1306-11. https://doi.org/10.1128/AAC.49.4.1306-1311.2005

13. Lyczak JB, Cannon CL, Pier GB. Establishment of Pseudomonas aeruginosa infection: lessons from a versatile opportunist. Microbes Infec 2000; 2:1051-1060. https://doi.org/10.1016/S1286-4579(00)01259-4

14. Van Delden C, Iglewski B H. Cell-to-cell signaling and Pseudomonas aeruginosa infections. Emerging Infecet Dis 1998; 4 (4):1-4.https://doi.org/10.3201/eid0404.980405

15. Zhanel G G, DeCorby M, Adam H, et al. Prevalence of antimicrobial-resistant pathogens in Canadian hospitals: results of the Canadian Ward Surveillance Study (CANWARD 2008). Antimic Agents Chemoth 2010; 54(11):4684-4693. https://doi.org/10.1128/AAC.00469-10

16. Lambert ML, Suetens C, Savey A, et al. Clinical outcomes of health-care-associated infections and antimicrobial resistance in patients admitted to European intensive-care units: a cohort study. The Lancet Infect Dis 2011; 11(1):3038.https://doi.org/10.1016/S1473-3099(10)70258-9

17. Keen E F, Robinson B J, Hospenthal DR, et al. Prevalence of multidrug-resistant organisms recovered at a military burn center. Burns 2010; 36(6):819-825. https://doi.org/10.1016/j.burns.2009.10.013 
18. Tumbarello M, Repetto E, Trecarichi EM, et al. Multidrug-resistant Pseudomonas aeruginosa bloodstream infections: risk factors and mortality. Epidem Infect 2011; 139(11): 1740-1749. https://doi.org/10.1017/S0950268810003055

19. Harris AD, Perencevich E, Roghmann MC, et al. Risk factors for piperacillin-tazobactam-resistant Pseudomonas aeruginosa among hospitalized patients. Antimicro Agents Chemoth 2002; 46(3):854-858

https://doi.org/10.1128/AAC.46.3.854-858.2002

20. Zhao WH, Hu ZQ. Beta-lactamases identified in clinical isolates of Pseudomonas aeruginosa. Critical Rev Microbiol 2010; 36(3):245-258.

https://doi.org/10.3109/1040841X.2010.481763
21. Ramirez MS, Tolmasky ME. Aminoglycoside modifying enzymes. Drug Resis Upd 2010; 13(6), 151-171. https://doi.org/10.1016/j.drup.2010.08.003

22. Strateva T, Yordanov V. Pseudomonas aeruginosa- a phenomenon of bacterial resistance. J Med Microb 2009; 58(9):1133-1148. https://doi.org/10.1099/jmm.0.009142-0

23. Zavascki AP, Goldani LZ, Li J, Nation RL. Polymyxin B for the treatment of multidrug-resistant pathogens: a critical review. J Antimic Chemo 2007; 60(6):1206-1215. https://doi.org/10.1093/jac/dkm357

24. Molina J, Cordero E, Pachón J. New information about the polymyxin /colistin class of antibiotics. Expert Opin Pharm 2009; 10(17):2811-2828. https://doi.org/10.1517/14656560903334185 